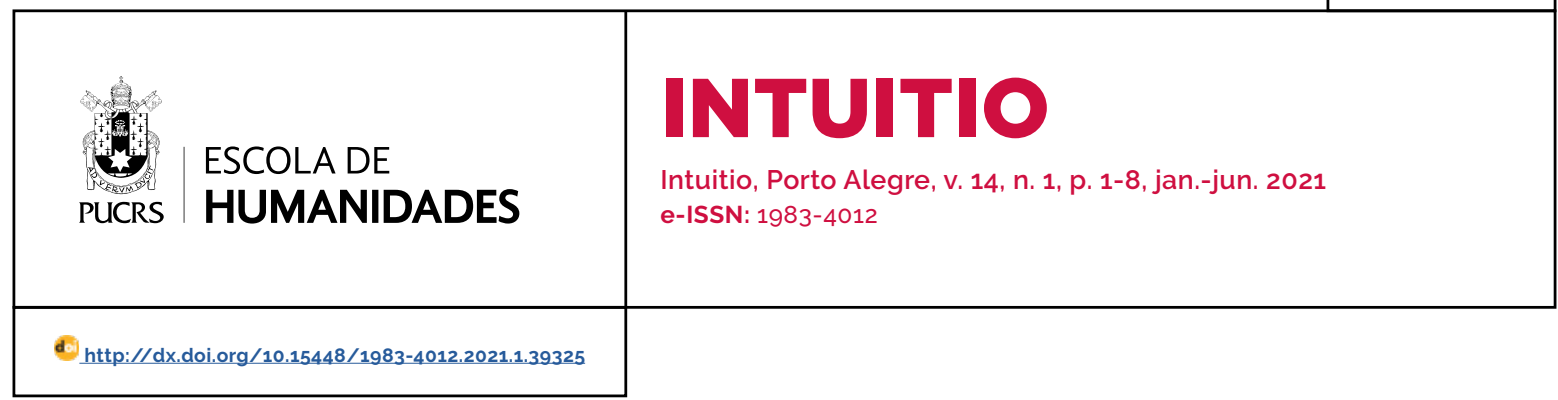

SEÇÃO: ARTIGO

\title{
Nietzsche como parte da história da metafísica
}

Nietzsche as part of the history of metaphysics

\section{Barbara Smolniakof ${ }^{1}$ \\ orcid.org/0000-0002-4998-144X \\ barbarasmolniakof@gmail.com}

Recebido em: 8 out. 2020. Aprovado em: 20 fev. 2021. Publicado em: 02 set. 2021.

\section{(c) (i)}

Artigo está licenciado sob forma de uma licença Creative Commons Atribuição 4.0 Internacional.
Resumo: É notório que a leitura que Heidegger fez da filosofia nietzschiana foi uma das mais polêmicas. Sobretudo, porque ele insistiu em enquadrar Nietzsche na metafísica. Este trabalho explicita de que modo Nietzsche é compreendido como parte da história da metafísica sob a perspectiva de Heidegger. Para tanto, é necessário dar dois passos gerais. Primeiro, apontar o que Heidegger entende por metafísica, a saber, a história da filosofia como o esquecimento do Ser. Segundo, fazer uma leitura pormenorizada do ensaio "A sentença nietzschiana 'Deus está morto'" reconstruindo o argumento de Heidegger. Nesse ensaio ele localiza a filosofia de Nietzsche dentro da metafísica, mais exatamente, como a parte que a esgota.

Palavras-chave: Metafísica. Nietzsche. Heidegger. Valor.

Abstract: It is clear that Heidegger's reading of Nietzschean philosophy was one of the most polemic. Especially because he insisted on framing Nietzsche in metaphysics. This work explains how Nietzsche is understood as part of the history of metaphysics under Heidegger's perspective. For that, it is necessary to take two general steps. First, to point out what Heidegger means by metaphysics, namely, the history of philosophy as the forgetfulness of Being. Second, to make a detailed reading of the essay "the Nietzschean sentence 'God is dead'" reconstructing Heidegger's argument. In this essay he locates Nietzsche's philosophy within metaphysics, more precisely, as the part that exhausts it.

Keywords: Metaphysics. Nietzsche. Heidegger. Value.

\section{Introdução}

A leitura que Heidegger fez da filosofia de Friedrich Nietzsche foi uma das mais polêmicas já registrada. Em parte, porque ela não é apenas um comentário da filosofia nietzschiana, ao falar de Nietzsche, Heidegger está também falando de sua própria filosofia. Em parte, porque Heidegger parte de alguns elementos que são dos mais fundamentais do pensamento nietzschiano e lhes dá uma "roupagem" especifica, de modo a apresentá-lo como a reversão do platonismo e a consumação da metafísica.

Já no início de seu ensaio "A sentença nietzschiana 'Deus está morto'", Heidegger aponta que irá tratar da essência do niilismo a partir de uma caracterização da filosofia de Nietzsche como o estágio final da metafísica Ocidental (HEIDEGGER, 2003, p. 471-472). E, para compreender de que maneira Heidegger vê Nietzsche como parte constituinte da história da metafísica, é preciso antes entender o que precisamente Heidegger tem em mente ao falar de metafísica. Por isso, antes de nos determos à leitura 
de Heidegger sobre Nietzsche, detenhamo-nos brevemente à noção heideggeriana de metafísica.

Por metafísica, Heidegger entende a própria história da Filosofia, que inicia com Platão, e toma como fio condutor do pensamento o ente. Platão foi o primeiro a rejeitar a noção de "verdade" entendida pelos filósofos antigos como "desvelamento" (alétheia) do Ser. Além disso, ele subverteu a relação entre esses dois elementos tomando o ser como algo derivado da verdade. Foi o passo inicial para causar uma confusão entre ser e ente e adotar o ser como se fosse um ente em geral ou a soma de todos os entes da totalidade. Nesse sentido, Platão é caracterizado por Heidegger como o primeiro metafísico, justamente por ser o primeiro a esquecer ou ignorar a diferença ontológica entre ser e ente e assumir o ente enquanto o próprio ser.

A partir daí, ao invés dos filósofos pensarem o ser propriamente dito, passaram a pensar apenas o ser de um ente específico. Foi o caso, por exemplo, das ideias platônicas, do Deus e da alma pensados a partir dos medievais e da razão e do sujeito pelos modernos. Este movimento de pensar o ser de um ente em particular deixou a verdade do Ser impensada ou "velada" pelo pensamento desse ente. É isso o que Heidegger parece afirmar a seguir:

O pensamento é ininterruptamente tocado pelo acontecimento uno de que o ente é pensado desde o início da história do pensamento ocidental em função do Ser, de que a verdade do Ser permanece contudo impensada e enquanto experiência possivel não apenas negada ao pensamento (HEIDEGGER, 2003, p. 474).

Entendamos aqui "ente" como tudo aquilo que é, de que se pode dizer algo ou definir de alguma forma; assim, tudo que existe no mundo é um ente. Ora, na medida em que se assume qualquer ente particular como guia do pensamento, o que ocorre é o esquecimento do Ser e da verdade do Ser, que é exatamente aquilo a que compete ao homem pensar. O curioso é que, ao mesmo tempo em que é o Ser que deve ser pensado, ele não pode ser definido, pois não pode ser expresso linguisticamente. $E$ isto ocorre porque a linguagem do homem se limita a descrever, predicar ou definir entes (ou seja, aquilo que é delimitado de determinada forma), mas não alcança o Ser, que escapa à linguagem.

\section{Niilismo e Metafísica}

Da caracterização da história, não como uma sequência das eras, mas como etapas do esquecimento do Ser causado pelo pensamento do ente, Heidegger passa à discussão sobre Nietzsche e sua filosofia vista sob o signo do niilismo como esgotamento da metafísica moderna. Esta é inaugurada por Descartes e o pensamento do Cogito. A partir da transformação do pensamento em representação (de um sujeito sobre um objeto), a relação ser e ente se transforma em sujeito e objeto e o ente passa a ser visto como objeto, ou seja, o ente é algo somente na medida em que puder ser representado pelo homem enquanto sujeito que representa. Esse movimento se desvia também da noção de verdade como desvelamento e a interpreta como certeza: o que é certo (verdadeiro) é tudo o que é concebido pelo intelecto do sujeito, que representa, através de ideias claras e distintas. Hegel, Kant e Leibniz também são elencados como grandes expoentes da metafísica moderna, mas é em Nietzsche que ela tem seu acabamento na medida em que ele pensa o niilismo.

O niilismo é caracterizado como um movimento histórico que designa o destino de dois mil anos da história do ocidente e é sintetizado na frase "Deus está morto". Heidegger recorre aos textos nietzschianos para elucidar onde e de que modo Nietzsche fala da morte de Deus. E ele a anuncia n'A Gaia Ciência (1882) no aforismo 125 intitulado o "Homem Louco":

\footnotetext{
Não ouviram falar daquele homem louco que em plena manhã acendeu uma lanterna e correu ao mercado, e pôs-se a gritar incessantemente: "Procuro Deus! Procuro Deus!"? - E como lá se encontrassem muitos daqueles que não criam de Deus, ele despertou com isso uma grande gargalhada. Então ele está perdido? Perguntou um deles. Ele se perdeu como uma criança? Disse um outro. Está se escondendo? Ele tem medo de nós? Embarcou num navio? Emigrou? - gritavam e riam uns para os outros. O homem louco se lançou no meio deles e trespassou-os com seu olhar. "Para onde foi Deus?" gritou ele, "já lhes direi! Nós o matamos - vocês e eu. Somos todos seus assassinos!
} 
Mas como fizemos isso? Como conseguimos beber inteiramente o mar? Quem nos deu a esponja para apagar o horizonte? Que fizemos nós, ao desatar a terra de seu sol? Para onde se move ela agora? Para onde nos movemos nós? Para longe de todos os sóis? Não caímos continuamente? Para trás, para todos os lados, para a frente, em todas as direções? Existem ainda um "em cima" e um "embaixo"? Não vagamos como que através de um nada infinito? Não sentimos na pele o sopro do vácuo? Não se tornou ele mais frio? Não anoitece eternamente? Não temos que acender lanternas de manhã? Não ouvimos o barulho dos coveiros a enterrar Deus? Não sentimos o cheiro da putrefação divina? - também os deuses apodrecem! Deus está morto! Deus continua morto e fomos nós que o matamos! Como nos consolamos nós assassinos dentre todos os assassinos? O mais forte e mais sagrado que o mundo até então possuíra sangrou inteiro sobre nossos punhais (NIETZSCHE, 2002, § 125).

Este anúncio é mais do que a manifestação de um ateu a respeito da inexistência de um ser superior. Ao interpretar a sentença "Deus está morto" em sentido de descrença, ela é tomada teológico-apologeticamente, enquanto o que está em questão de fato para Nietzsche ao expressá-la, isto é, o pensamento sobre o que já aconteceu com a verdade do mundo suprassensível, é deixado de lado.

Nesse sentido, a morte de Deus designa um abalo metafísico causado pela derrocada da divisão metafísica-cristã entre mundo sensivel e suprassensivel. A figura religiosa de Deus representava o mundo suprassensivel dos ideais, que determina a vida terrena com uma meta a partir de cima e de fora dela. Em outras palavras, a morte de Deus enuncia o fim da metafísica entendida por Nietzsche como platonismo. O mundo suprassensivel, inteligivel, seria o propriamente real e verdadeiro, enquanto o mundo sensivel é apenas transitório, ilusório e aparente. Se Deus, enquanto a ideia de Deus cristão que representa o mundo suprassensivel, "morre", então, este solo suprassensivel perde sua força de atuação sobre o mundo sensivel. Nas palavras de Heidegger: "ele não fomenta mais vida alguma" (HEIDEGGER, 2003, p. 478), ou seja, ele não serve mais como horizonte de sentido e avaliação para o mundo sensivel. Com a morte de Deus como a representação do niilismo, acontece o nada de ser, "Nada significa aqui: ausência de um mundo suprassensivel, imperativo" (HEIDEGGER, 2003, p. 479).

Ao recorrer aos escritos de 1887, Heidegger constata a relação entre niilismo e valor, ou melhor, ausência de valor, uma vez que Nietzsche responde à pergunta "o que é o niilismo?" com "o fato de os valores mais elevados se desvalorizarem (NIETZSCHE, 2008, p. 241). Niilismo, portanto, representa a desvalorização dos mais altos valores e, na medida em que Nietzsche o interpreta como a desvalorização dos mais altos valores até aqui, trata-se de um processo histórico. Estes mais altos valores que foram desvalorizados são Deus, o próprio mundo suprassensivel, as metas e ideais, as ideias de bem, belo e verdadeiro. E, para Heidegger, quando Nietzsche diz "o verdadeiro" ele se refere ao efetivamente ente, "o bem" se refere àquilo de que tudo depende e "o belo" à ordem e unidade do ente na totalidade (HEIDEGGER, 2003, p. 484). Segundo Heidegger, a desvalorização desses valores é efetivada com a intelecção (talvez Heidegger esteja aqui fazendo referência ao periodo moderno) de que o mundo ideal (ou as metas estabelecidas por seus valores superiores) não é realizável na esfera sensivel. Ou seja, de que adiantam estes valores se eles não podem ser efetivados?

Porém, Heidegger salienta que o niilismo é plurissignificativo, ou seja, ele não tem apenas o sentido negativo da desvalorização dos valores supremos. Niilismo, como desvalorização e reconhecimento do mundo desprovido de valores, implica em uma nova instauração de valores. Contudo, a nova instauração não deve ser feita a partir da mesma base suprassensivel. Embora Deus tenha morrido, o lugar ocupado por ele permanece, mesmo que esvaziado. Se assumi-lo como ponto de partida para uma nova instauração, o que ocorre é apenas uma substituição dos ideais antigos por novos ideais: é o que acontece com as doutrinas modernas de felicidade, socialismo, progresso, autonomia e liberdade, por exemplo. Esta nova instauração que parte da mesma base suprassensivel deixada pelo Deus morto é chamada de niilismo incompleto, ou não plenificado, porque o homem procura superar 
sua condição niilista sem uma transvaloração dos valores. Embora o ideal suprassensivel de Deus tenha desaparecido, o âmbito suprassensivel ocupado por ele ainda é mantido, ou seja, o critério de avaliação ou instauração de valores permanece o mesmo.

Em contrapartida, o niilismo se caracterizaria como plenificado, ou completo, a partir do abandono do próprio âmbito suprassensivel e de uma mudança no modo de valoração e no princípio de avaliação: "o princípio não pode ser mais o mundo suprassensivel que perdeu sua vitalidade" (HEIDEGGER, 2003, p. 487). Ou seja, a transvaloração dos valores como uma mudança, não apenas de valores, mas do próprio principio avaliativo, é o que caracteriza o sentido positivo do niilismo, pois na medida em que o âmbito suprassensivel perdeu sua vitalidade, a transvaloração deve buscar outro âmbito e modo de avaliação, que são encontrados na própria vida ou no que é maximamente vital.

Ora, o niilismo é a história que trata dos valores: da desvalorização dos valores mais elevados até aqui, da necessidade de uma instauração de novos valores, de uma transvaloração de todos os valores, da busca de um novo princípio de toda avaliação. Por isso, o valor parece ser de fundamental importância para uma compreensão mais completa do fenômeno do niilismo tal como Nietzsche o apresenta.

"O que Nietzsche entende por valor? Onde está fundada a essência do valor? Por que a metafisica nietzschiana é uma metafísica dos valores?" (HEIDEGGER, 2003, p. 489). Tais perguntas são fundamentais para elucidar o niilismo, pois dado que esse é designado como a desvalorização dos valores, é preciso entender o que é o valor, em sentido nietzschiano, para entender plenamente o que é o niilismo tal como Nietzsche o apresenta através da sentença "Deus está morto". Heidegger elenca Nietzsche como um dos responsáveis a impulsionar a discussão sobre os valores na filosofia. Desde valores vitais e culturais até uma hierarquia de valores, o "valor" passa a ser corrente a partir do século XIX por ser este conceito um tanto quanto indeterminado.

\section{Valor versus Ser}

Ele recorre novamente aos textos nietzschianos para a apresentação do que Nietzsche entende por valor. Em um fragmento póstumo de 1887/1888, o valor é apresentado como perspectiva: "O ponto de vista do 'valor' é o ponto de vista das condições de conservação-elevação em vista de conformações complexas de duração no interior do devir" (NIETZSCHE, 2008, p. 388). Enquanto ponto de vista, o valor é lançado a partir do olhar que vê e para o próprio olhar que vê, ou seja, é relativo a quem o estabelece como perspectiva. Nesse sentido, os valores não são em si mesmos, mas são em relação a quem vê. Como pontos de vista, os valores são sempre condições, ao mesmo tempo, de conservação e elevação; "onde os valores são estabelecidos, os dois tipos de condicionamento sempre precisam ser apreendidos conjuntamente pelo olhar" (HEIDEGGER, 2003, p. 490). O valor enquanto ponto de vista é estabelecido como representação do ente, que é apreendida sob o traço da aspiração, ou seja, parece que o valor é estabelecido como ponto de vista a partir de e em função de uma aspiração; e o ente que representa, aspira ser em sua essência, ao mesmo tempo, algo conservado e, também, elevado, ou seja, ele não aspira apenas permanecer do mesmo modo como está, mas aspira ser mais do que ele é.

Ora, conservação e elevação são traços fundamentais da própria vida. A conservação de uma vida é dada em função de sua elevação e seu querer-crescer. Uma vida que apenas é conservada, mas não cresce, é decadente. ${ }^{2}$ Por isso, a elevação é o que caracterizaria, em termos heideggerianos, a "essência" da vida. Na medida em que o valor é um ponto de vista lançado pelo olhar que aspira conservação e elevação; e, na medida em que conservação e elevação são

\footnotetext{
2 Não nos deteremos à noção de decadência neste trabalho, ela apareceu mais porque tratamos do conceito de vida. À guisa de mais esclarecimentos recomendamos a leitura de alguns fragmentos póstumos de Nietzsche, onde ele trata da decadência mais detidamente. Cf NIETZCHE, FP novembro de 1887 - março de 1888, 11 [227]; NIETZSCHE FP primavera de 1888, 14 [75]. Cf. também MARTON, 2016, p. 179-180.
} 
condições necessárias à vida, então o valor é instaurado pela própria vida, através do vivente enquanto uma "conformação complexa da vida" (ou seja, o organismo que vive), pois está associado aos dois traços que a caracterizam.

Nietzsche caracteriza o valor como atuante no âmbito do devir. Para Heidegger, "devir", em Nietzsche, é o traço fundamental de todo real, isto é, do ente em sentido amplo. E este "ente em sentido amplo" designa para Heidegger o conceito nietzschiano de vontade de poder. $O$ valor, portanto, pertence à vontade de poder. Ora, "devir" é "vontade de poder", que também é "vida". Nesse sentido, estes termos designam a mesma coisa ou no limite são interdependentes; relacionam-se de modo tal que a vida (que se manifesta no vivente) está no devir em relação a centros da vontade de poder, isto é, conformações de domínio, que, segundo Heidegger, são os âmbitos nos quais o vivente vive ou atua elaborando pontos de vista como condições de conservação e de elevação (ou seja, o valor). A arte, o Estado, a religião, a ciência, e a própria sociedade são propriamente estes centros de vontade de poder. Dessa relação entre vida, valor e devir, onde o valor é condição de conservação e de elevação da vida, a qual está no devir que é vontade de poder, vê-se que a vontade de poder é o que possibilita a própria instauração de valores. Portanto, a vontade de poder é o principio de instauração dos valores.

Até aqui vê-se que Heidegger apresentou a compreensão da morte de Deus tal como Nietzsche a apresenta a partir de uma teia de conceitos. Ela só é completamente entendida se elucidado o que Nietzsche entende por niilismo, que, por sua vez, é compreendido somente se o conceito de valor for também compreendido; o qual encaminha para uma discussão necessária sobre a vontade de poder. Falar sobre esta é o último passo a ser dado para a compreensão da sentença "Deus está morto", pois o valor é instaurado a partir da vontade de poder, é ela que permite e até exige a avaliação. Portanto, ao falar de valor é necessário também falar de vontade de poder, a qual, por consequência, é de fundamental importância para entender suficientemente o niilismo.

A vontade de poder é reconhecida como o principio de instauração dos valores, ao mesmo tempo, ela é o principio de uma nova instauração de valores, ou seja, ela é o que possibilita a transvaloração. Pois, na medida em que se reconhece a vontade de poder como princípio de uma nova avaliação, a estrutura de uma instauração dos valores deixa de ser a suprassensivel que caiu por terra com a morte de Deus.

Para falar sobre a vontade de poder, Heidegger parte de um senso comum e toma o significado dos dois termos - "vontade" e "poder" - para definir o conceito "vontade de poder" como um todo. Nesse sentido, ao juntar "vontade" - um aspirar a algo - com "poder" - o exercício do poder e da violência - ter-se-ia em vontade "de" poder a aspiração por chegar ao poder. Enquanto aspiração do que ainda não possui (poder), a vontade de poder, a partir dessa interpretação, teria seu fundamento em uma sensação de falta. Dado que a aspiração por algo que falta é uma representação apreendida pelo conhecimento psicológico, a vontade de poder caberia ser pensada pela psicologia. Contudo, Heidegger salienta que tal interpretação vai longe do que Nietzsche de fato quer dizer com vontade de poder, não basta assumir o significado de dois termos separados e juntá-los em um só. Além do que, por "vontade" Nietzsche não se refere a uma faculdade, portanto, não cabe à psicologia explicá-la. Segundo Heidegger, a "vontade de poder" designa uma expressão fundamental da filosofia definitiva de Nietzsche, ou seja, trata-se de uma expressão fundamental de sua metafisica. E para compreendê-la tal como Nietzsche a apresenta, é necessário pensá-la na esteira de toda a história da metafísica ocidental.

O primeiro momento em que Nietzsche fala da vontade de poder é em Assim falou Zaratustra, onde ele relaciona vida, vontade de poder e obediência: "onde encontrei o vivente, ai encontrei vontade de poder; e mesmo na vontade do servo encontrei vontade de ser senhor" (NIETZSCHE, 1998, p. 127). O querer da vontade de poder tem 
a ver com domínio; querer (o aspecto da vontade em sentido mais amplo e da vontade de poder em sentido mais específico) é querer dominar. Nesse sentido, até mesmo na vontade do servo se encontra vontade de poder, ele quer ser senhor, mas não senhor de seu próprio senhor. Em outras palavras, o que ele quer não é sair de sua condição de servo para, a partir daí, tornar-se senhor, mas enquanto servo, na própria condição de servo, ele quer ter algo abaixo de si que comanda enquanto servo e do qual ele mesmo se serve.

Nesse sentido, o querer (que caracteriza a vontade de poder) é fundamentalmente comando, que é caracterizado, por sua vez, como uma disposição consciente das possibilidades da atuação ativa. No comando, o comandante obedece a essa disposição e, com isso, obedece a si mesmo. Nesse sentido, comando tem a ver com superar a si mesmo. Enquanto comando, a vontade não quer o que ela ainda não tem, mas o que já tem, ela quer a si mesma e, com isso, ultrapassar-se, quer vir a ser mais forte, isto é, ter mais poder, ou seja, comandar: "Poder só é então poder conquanto ele permanece elevação-de-poder e comanda para si mesmo o 'mais poder'" (HEIDEGGER, 2003, p. 495). O "poder" da expressão "vontade de poder" denota o modo como a vontade quer a si mesma, isto é, ela quer a si mesma na medida em que ela é comando e quer ser mais forte. Segundo Heidegger, enquanto essência da vontade, a vontade de poder é o traço fundamental de tudo o que é real, isto é, ela é a essência do ser de todo ente. E enquanto essência do ser, ela é o ente em sua totalidade. Por isso, esta expressão designa a metafísica de Nietzsche: é metafísica da vontade de poder. O poder é a condição de elevação da vontade de poder, ou seja, ela só é vontade de poder enquanto comanda para e se supera em direção a este mais poder. E, para alcançar mais poder e crescer enquanto vontade de poder, instaurar valores é justamente o que a vontade faz, uma vez que eles são a condição de conservação-elevação da vontade de poder.

A partir da consideração do ente pensado como vontade de poder, portanto, como instau- rador de valores, constata-se que a metafísica (nietzschiana) pensa a partir de valores. É a partir disso que Heidegger associa o pensamento nietzschiano da vontade de poder à metafísica da modernidade que tem sua essência na busca pela certeza. Segundo ele, "a certeza enquanto princípio da metafísica moderna só chega a ser verdadeiramente fundada no seio da vontade de poder" (HEIDEGGER, 2003, p. 499). Pois a vontade de poder assegura a necessidade da certeza, na medida em que assegura as condições de conservação enquanto representação moderna de verdade. A certeza, nesse sentido, é um valor, necessário à conservação daquele que a instaura. Com efeito, a "verdade" é definida como algo diferente a partir da metafísica da vontade de poder. Enquanto valor, a verdade não é o desvelamento do ser, mas uma condição de conservação-elevação a partir da qual a vontade de poder quer a si mesma.

Embora necessária, porque assegura a condição de conservação, a verdade enquanto valor não é suficiente para a elevação da vontade de poder. A condição suficiente para a elevação de mais força da vontade é a propriedade de criar advinda da arte, como a própria "essência de todo querer, que abre perspectivas e as controla" (HEIDEGGER, 2003, p. 502). Por ser uma condição que instiga a vontade a querer a si mesma e ir para além de si mesma, para alcance de mais poder, a arte é um valor. Portanto, verdade e arte são, respectivamente, as condições necessária e suficiente de conservação-elevação, que constituem a unidade essencial da vontade de poder. A essência metafísica do valor é determinada a partir dessa unidade essencial que constitui o ente enquanto tal, isto é, vontade de poder. Por pensar a partir da vontade de poder, o ser é esquecido ou escondido pelo pensamento do valor. Nesse sentido, Nietzsche faz parte da metafísica porque pensa um ente (o valor) no lugar do ser ou o assume como o próprio ser:

por si só, no que o ser é dignificado enquanto um valor, ele já é rebaixado a uma condição estabelecida pela própria vontade de poder. No que o ser mesmo é avaliado e assim dignificado, ele já foi anteriormente apartado da dignidade 
de sua essência. Se o ser do ente é alcunhado como um valor e se com isso a sua essência é marcada, então, no interior dessa metafísica, e isso significa sempre no interior da verdade do ente enquanto tal durante esta era, todo e qualquer caminho para a experiência do ser mesmo é extinto (HEIDEGGER, 2003, p. 518).

O ser, a partir da filosofia de Nietzsche, decai na medida em que é pensado como valor, ou seja, ele permanece velado pelo pensamento de outra coisa. Por isso, Nietzsche, para Heidegger, faz parte da história da metafísica. E na medida em que o pensamento valorativo assume como fio condutor os valores, sua instauração, desvalorização e transvaloração e, assim, pensa através de valores e reduz o próprio ser a um mero valor, ao invés de superar o niilismo, ele é o próprio acabamento do niilismo. Pois Heidegger entende niilismo como o que não tem nada com o ser ou no limite não possibilita sua realização.

\section{Considerações finais}

Nesse sentido, a transvaloração dos valores, que assume como principio instaurador a vontade de poder e o valor como condição de conservação-elevação desta, esgota o niilismo e a metafísica, é sua fase de acabamento na medida em que pensa o valor e não o ser. Nesse sentido, Heidegger identifica a história da metafísica ao niilismo afirmando que a essência do niilismo repousa na história na qual se perde o ser e sua verdade mediante a aparição do ente enquanto tal. Ora, se o niilismo é de fato a história da perda do ser e sua verdade devido o pensamento do ente enquanto tal, então a metafísica como história da verdade do ser é essencialmente niilista.

Em suma, o pensamento de Nietzsche é enquadrado por Heidegger como parte da história da metafísica na medida em que esta história é designada como esquecimento do Ser e na medida em que o pensamento nietzschiano se orienta segundo valores. Por pensar a desvalorização dos mais altos valores e a instauração de novos valores a partir da vontade de poder como novo principio instaurador, Nietzsche faz parte do próprio processo histórico que critica: o niilismo. E para Heidegger, niilismo é o modo como se esgota a própria metafísica, pois ao pensar o valor Nietzsche também se esquece ou mantém impossibilitada para o pensamento uma reflexão sobre o Ser.

\section{Referências}

BATISTA, João Bosco. A Crítica heideggeriana da Modernidade. In: DONATELLI, M.; MENEZES, E. (org.) Modernidade e a ideia de História. Ilhéus: Editora da Universidade Estadual de Santa Catarina, 2003. p. 234-247.

FERREIRA JUNIOR, Wanderley J. Heidegger leitor de Nietzsche: a metafísica da vontade de potência como consumação da metafísica ocidental. Transformação, Marilia, v. 36, n. 1, p. 101-116, jan./jun. 2013.

HEIDEGGER, Martin. A Sentença nietzschiana "Deus está morto". Natureza Humana, v. 5, n. 2, p. 471-526, jul./dez. 2003.

HEIDEGGER, Martin. Nietzsche I. Tradução de Marco Antonio Casanova. Rio de Janeiro: Forense Universitária, 2010

HEIDEGGER, Martin. Nietzsche II. Tradução de Marco Antonio Casanova. Rio de Janeiro: Forense Universitária, 2007

MARTON, Scarlett (ed.). Dicionário Nietzsche. São Paulo: Edições Loyola, 2016. (Sendas \& Veredas).

NIETZSCHE, Friedrich Wilhelm. A Gaia Ciência. São Paulo: Companhia das Letras, 2001.

NIETZSCHE, Friedrich Wilhelm. Assim Falou Zaratustra. Um livro para todos e para ninguém. 9. ed. Rio de Janeiro: Bertrand Brasil, 1998.

NIETZSCHE, Friedrich Wilhelm. Fragmentos Póstumos. Volumen IV (1885-1889). Edición realizada bajo los auspícios de la Sociedad Española de Estudios sobre Nietzsche (SEDEN). Traducción, introducción y notas de Diego Sánchez Meca y Jesús Conill. 2. ed. Madrid: Editorial Tecnos, 2008

NUNES, Benedito. Passagem para o poético: filosofia e poesia em Heidegger. São Paulo: Loyola, 2012.

REALE, Giovanni; ANTISERI, Dario. História da Filosofia: de Nietzsche à Escola de Frankfurt. São Paulo: Paulus, 2006. v. 6. (Coleção história da filosofia).

SILVA, José Roberto da. Nietzsche como decisão: a interpretação de Heidegger da sentença nietzschiana "Deus está Morto". Especiaria - Cadernos de Ciências Humanas, Ilhéus, v. 18, n. 32, p. 159-173, jan./jun. 2018.

\section{Barbara Smolniakof}

Graduada em Filosofia pela Universidade Estadual do Centro-Oeste (UNICENTRO), em Guarapuava, PR, Brasil; mestrado em andamento em Filosofia pela Universidade Federal de Santa Catarina (UFSC), em Florianópolis, SC, Brasil. 


\section{Endereço para correspondência}

Barbara Smolniakof

Universidade Federal de Santa Catarina

R. Eng. Agronômico Andrei Cristian Ferreira, s/n

Trindade, 88040-900

Florianópolis, SC, Brasil

Os textos deste artigo foram revisados pela Poá Comunicação e submetidos para validação da autora antes da publicação. 